\title{
Investigations on the mechanical strength of enamelled glass
}

\author{
Iris Maniatis • Michael Elstner
}

Received: 12 January 2016 / Accepted: 24 April 2016 / Published online: 13 May 2016

(C) Springer International Publishing Switzerland 2016

\begin{abstract}
Enamelled glass has been used for many years in architectural applications. It is well known that ceramic frits have a weakening effect on the mechanical strength of thermally toughened glass. This fact is addressed in the relevant European product standards for thermally toughened (with or without heat soak test) and heat strengthened glass. In EN 121501 the minimum bending strength of thermally toughened enamelled glass is given with $\sigma_{\mathrm{bB}}=75 \mathrm{~N} / \mathrm{mm}^{2}$ and in EN 1863 for heat strengthened glass the value is given with $\sigma_{\mathrm{bB}}=45 \mathrm{~N} / \mathrm{mm}^{2}$. The values are valid independently of the colour tint and the manufacturing process of the enamel coating. As the experimental data for the current values were determined decades ago and the background of these investigations is not available anymore, a recent research project examined influences of glass type, colour tint and the manufacturing process of the enamel by performing four point bending tests according to EN 1288-3. To compare the results with the non enamelled glass types the glass samples were taken from a single float glass batch. The test results show the strength is mainly dependent on the colour scheme, the thickness of the enamel and the temperature sequence of the fusing process itself. In the paper some of the results will be presented especially
\end{abstract}

I. Maniatis $(\square)$

Universität der Bundeswehr München, Neubiberg,

Germany

e-mail: iris.maniatis@unibw.de

M. Elstner

AGC Interpane, Plattling, Germany the influence of different parameters on the mechanical strength. Furthermore the results will be compared with the current values of the minimum bending strength given in the product standards.

Keywords Enamelled glass - Bending strength · Colour $\cdot$ Manufacturing process

\section{General}

\subsection{Definitions}

An enamel is a glass-like mass which is produced by total or partial fusing principally consisting of oxides. It is applied in one or several layers together with various supplements to metallic or glass surfaces at temperatures over $450^{\circ} \mathrm{C}$ (Krampe 2013, Technische Regel RAL-RG 529 A3 2007). The term "enamel" is used for the final printed surface. The term "enamelling" is used for the manufacturing process.

\subsection{Colour scheme}

Essentially the dye powder consists of the following main components: flow system (70-95\%) and pigment system $(5-30 \%)$. After firing the transparent and soft glass-flow surrounds the colour pigments contained in the dye and binds these together permanently. The adhesion to the glass results from ionic bondings of the $\mathrm{SiO}$ groups (Krampe 2013). Table 1 lists the most 
Table 1 Components of the colours black, red and white as per manufacturer's specifications

Technical Information Ferro 2012

Table 2 Bending tensile strength for FT and HS glass

\begin{tabular}{llll}
\hline & Black & Red & White \\
\hline Flow system & $\mathrm{ZnO}-\mathrm{B}_{2} \mathrm{O}_{3}-\mathrm{SiO}_{2}$ & $\mathrm{ZnO}-\mathrm{B}_{2} \mathrm{O}_{3}-\mathrm{SiO}_{2}$ & $\mathrm{ZnO}-\mathrm{B}_{2} \mathrm{O}_{3}-\mathrm{SiO}_{2}$ \\
Pigment system & $\mathrm{CuO}-\mathrm{Cr}_{2} \mathrm{O}_{3}$ & $\mathrm{Cd}-\mathrm{S}-\mathrm{Se}$ & $\mathrm{TiO}_{2}$ \\
Particle size $(\mu \mathrm{m})$ & 9 & 7 & 9 \\
$\begin{array}{l}\text { Density }\left(\mathrm{kg} / \mathrm{dm}^{3}\right) \\
\begin{array}{l}\text { Linear thermal expansion } \\
\text { coefficient }(1 / \mathrm{K})\end{array}\end{array}$ & 3.0 & 2.9 & 3.2 \\
& $93 \times 10^{-7}$ & $93 \times 10^{-7}$ & $93 \times 10^{-7}$ \\
\hline
\end{tabular}

\begin{tabular}{lll}
\hline Glass type & \multicolumn{2}{l}{ Minimum values for bending tensile strength $\left(\mathrm{N} / \mathrm{mm}^{2}\right)$} \\
\cline { 2 - 3 } & $\begin{array}{l}\text { FT glass according } \\
\text { to EN 12150-1 }\end{array}$ & $\begin{array}{l}\text { HS glass according } \\
\text { to EN 1863-1 }\end{array}$ \\
\hline $\begin{array}{l}\text { Float: clear, tinted, coated } \\
\begin{array}{l}\text { Enamelled float glass } \\
\text { (enamelled surface under }\end{array}\end{array}$ & 120 & 70 \\
$\begin{array}{l}\text { tensile stress) } \\
\text { Reduction in strength }(\%)\end{array}$ & 75 & 45 \\
\hline
\end{tabular}

important components for the colours examined in the research project (black, red and white).

\subsection{Strength}

From an architectural and manufacturer's perspective important considerations for enamelled glass are: aesthetics, function (i.e. use as solar-control glass with an additional functional coating added to the enamelled surface), manufacturing process, visual assessment and application.

However for the proper dimensioning of the glazing, the characteristic strength values of the glass types must be known. The values given in EN 12150-1 (EN 12150-1:2000-11) and EN 1863-1 (EN 1863-1:201202) for enamelled thermally toughened safety glass (fully toughened glass-FT) with or without heat soak test (HST) and heat strengthened glass (HS) have been used for many years (see Table 2). The reduced values compared with those of non enamelled glass show that such ceramic frits have a weakening effect on the mechanical strength of thermally toughened glass. The values are independent of the colour tint and the manufacturing process of the enamel coating.
The experimental data for the current values were determined decades ago and the scientific background of these investigations is unknown. Up to now there have been only a few systematic investigations examining the reasons for the reduction in strength (see Krampe 2013). In (Krampe 2013) following feasible causes for the stress reduction are given:

- Differentials in thermal expansion coefficient

- Fineness of grind

- Firing penetration and porosity of the enamel

- Leaching processes within the boundary layer of the glass to the enamel

- Changes in thermal conditions during the firing process

In (Krampe 2013) the thermal conditions during the thermal toughening process are examined in detail.

\section{Manufacturing}

\subsection{Colour application process}

There exist different processes for applying the colour on the glass surface. These are, essentially: roller coating, screen printing, digital printing, and "curtain" coating. Usually the enamel coating is applied on the "air 
surface" of the float glass (that is to say, on the opposite side to the tin bath surface). During the thermal toughening process of thermally toughened safety glass or heat strengthened glass the ceramic coating is fused and firmly bound together with the glass. In Sect. 2.2 these processes are described according to (BF-Bulletin 015 2014).

\subsubsection{Roller coating}

The flat glass plane is passed beneath a ribbed rubber roller which transfers the enamel paint onto the surface of the glass. This ensures a regular, even and homogeneous distribution of the paint across the entire surface of the pane. Typically, the ribbed pattern of the roller is visible if the pane is examined from up close (on the enamelled side). Normally, however, these "ribs" are barely visible when the glass is observed from the front side (looking through the pane). Furthermore, a so-called "starry sky" effect (numerous very small imperfections) can sometimes emerge in the enamel. Due to the nature of this application process a certain "colour overrun" is possible on all edges of the pane, this overrun can be slightly corrugated especially on longitudinal edges (viewed in the direction of the movement of the roller unit). The edge surface, however, remains, as a rule, paint-free. For this reason, the manufacturer should be consulted beforehand about the position of installation. Usually roller printed enamelled glasses are not suitable for vision glass applications, if so these must always be discussed with the manufacturer beforehand.

\subsubsection{Screen printing}

In contrast to the printing process just described, within this process the paint can either be applied across the entire surface or, alternatively, in defined areas. The colour is applied to the glass surface on a horizontal screen printing frame through a narrow-meshed screen using a flood bar. The thickness of paint applied depends on the breadth of the screen's meshes and on the thread diameter. However the paint application is generally thinner than using roller or "curtain" coating and appears, depending on the colour chosen, either opaque or translucent. Typical for this manufacturing process are minor stripes both in the direction of printing and also transversal to this direction, as well as certain occasionally occurring spots of haze.
Using the screen printing process the glass edges generally remain paint-free but can display a slight bulging or beading of colour in the border area. If applications with visible edges are planned the manufacturer must be informed beforehand. With this process it is possible to carry out multi-coloured printings: for example, a so-called "double screen printing" whereby two different colours are recognizable on each panesurface looked at. The manufacturer should always be consulted on issues of tolerances (e.g. of congruency). The printing of selected patterned glass panes is also possible but, once again, the manufacturer should be consulted about it beforehand.

\subsubsection{Digital printing}

The ceramic colour is applied directly onto the glass surface using a process which is comparable to an inkjet printer. The thickness of colour application can vary and is generally thinner than using roller coating, screen printing or "curtain" coating processes. It appears, depending on the colour chosen, either opaque or translucent. A high print resolution of up to 720 dpi is possible at present. Typical for this manufacturing process are minor visible stripes in the direction of printing which are unavoidable due to the production technique. Using the digital printing process the glass edges generally remain paint-free but can display a slight bulging or beading of colour in the border area. If applications with visible edges are planned the manufacturer must be informed beforehand. The printing edges are, in the direction of printing, exactly straight but are, transversal to the print direction, slightly serrated. A certain paint spray may also occur along the printing edges. In the case of dot-, hole- and textmotifs the printing edges may display a serration which, like the mentioned spray, is only visible if the pane is examined from up close. Above all the digital printing process is suitable for complex multi-coloured grid designs or for images. It is less suitable for monochrome printing across the entire surface of a glass pane.

\subsection{4 "Curtain" coating}

The glass pane passes horizontally a so-called "curtain" and its entire surface becomes covered with colour. By adjusting the quantity of paint poured out and the speed with which the pane passes through the "curtain", the 
thickness of the coating can be controlled within a relatively wide range. In case of a slight uneven pouring lip stripes of various degrees of thickness in longitudinal direction (direction of pouring) can be caused. Vision glass applications must always be discussed with the manufacturer beforehand. The "colour overrun" at the edges is significantly greater than in the case of roller coating and can only be avoided through great effort. If paint-free visible edges are wanted, this must be specified when placing the order.

\subsubsection{Summary}

Depending on the chosen application process the colours need to have different viscosities. For roller coating, for example, more liquid colours are required (i.e. with a higher organic part). Correspondingly each different application procedure will require a different drying time. After the application of the colour the printed pane has to be dried (at a temperature of approximately $170-190^{\circ} \mathrm{C}$ ). Then the pane is thermally toughened and at the same time the enamel coating is fused onto the surface of the glass.

As already mentioned depending on the chosen manufacturing process different thicknesses of the enamel coating will result (see Fig. 1).

The colour systems currently available are capable to represent a large number of colours, like for example those of RAL and NCS chart of colour range. In order to achieve a specific colour the manufacturers of such colour systems provide recommendations regard-

\begin{tabular}{|c|c|c|}
\hline Method & Symbol & Thickness $[\mu \mathrm{m}]$ \\
\hline Digital Print & - & $15-20$ \\
\hline Screen Print & & $25-35$ \\
\hline Spraying & & $10-250$ \\
\hline Roller Coating & & $50-150$ \\
\hline Curtain Coating & & $150-350$ \\
\hline
\end{tabular}

Fig. 1 Different enamel application processes with average coating thicknesses (after fusing process) (Krampe 2013) ing which products need to be applied in which percentages.

\subsection{Fusing process}

At a furnace temperature of approximately $620-720^{\circ} \mathrm{C}$ (corresponding to glass temperatures of approximately $620-660^{\circ} \mathrm{C}$ ) the ceramic colour is fused into the glass. The total fusing cycle required amounts to approximately $40 \mathrm{~s}$ per millimetre of glass thickness. For proper fusing an oxidizing atmosphere in the furnace must be maintained.

Should the enamel prove to be porous after the fusing process, for example due to unfavourable fusing conditions, it can lead to a negative influence on the weather resistance, the chemical stability and the mechanical strength of the enamelled glass. In (Technical Information Ferro 2012) several possible ways of avoiding this are listed:

- Improving the drying of the enamel coating before fusing to optimise the burning of the organic medium

- Increasing the quantity of energy available for the fusing of the colour into the glass by optimising the fusing conditions (raising of the temperature) or

- Lowering the fusing temperature of the glass enamel by admixture of some transparent flowsystem

The enamel produced in this way will be scratch-proof as well as weather, UV and solvent resistant.

\section{Quality control}

To check the quality of the enamel the following, among others, test methods are recommended according to (Technical Information Ferro 2012):

- Gloss value as according to EN ISO 2813

- Surface scratch resistance as according to EN 15771 or ISO 1518

- Un-dried (wet) thickness of the enamel coating or the degree of porosity of the fused ceramic coating

The evaluation of the visual quality of glass panes enamelled across the whole or part of their surface can be carried out in accordance with the method described in (BF-Bulletin 015 2014). 


\section{Current research}

\subsection{General}

Based on the scientific literature explaining the reduction in mechanical strength of enamelled glass in the current research project (Siebert and Maniatis 2015) further investigation has been performed.

Samples of different glass types (HS, FT, FT with HST), different colours (red, black and white) and different application processes (screen printing and roller coating) were subjected to four point bending tests according to EN 1288-3 (EN 1288-3: 2000-09). The average coating thickness for screen printed glass was $45 \mu \mathrm{m}$ and for roller coated glass $75 \mu \mathrm{m}$. All specimen were sprinkled with corundum before testing to reduce the dispersion of failure stresses. For evaluation only specimen were used having their fracture origin in the area between the bending rollers of the four point bending test-setup.

The results were compared with un-enamelled panes of respectively each of the glass-types used. In order to make possible a comparison between the glass-types and between enamelled and un-enamelled glass, float glass of a single batch was used. For each series 10 samples with a nominal glass thickness of $8 \mathrm{~mm}$ were tested.
In the following sections the results obtained from the individual series are presented in stress-deformation diagrams. These are divided up according to application processes and glass-types. Statistical evaluation was performed using standardised normal distribution. Evaluation using Weibull distribution produced somewhat lower results and required more spot checks. The Anderson-Darling test was used in order to determine which of the two statistical evaluations is more suitable. Both statistical methods are more or less equally suitable.

In addition the crack origins of some samples were examined microscopically in order to analyse the fracture mirror.

\subsection{Four point bending test results}

\subsubsection{Heat strengthened (HS) glass series}

In Figs. 2 and 3 the failure stress values are given for each manufacturing process. Also shown are the failure stress values for the un-enamelled reference samples. The statistical evaluation of all series is listed in Table 3.

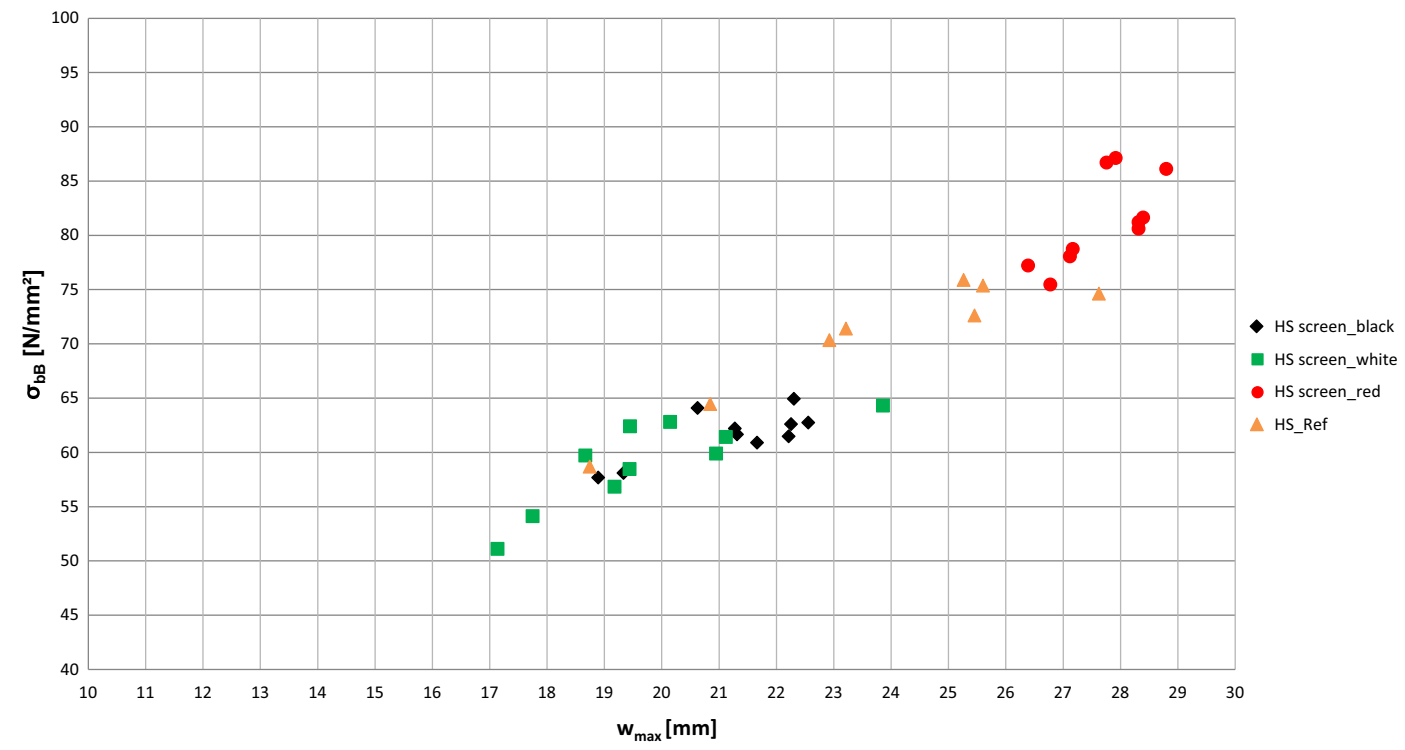

Fig. 2 Results for series 'HS glass with screen printing on side exposed to tensile bending stress'. (Color figure online) 


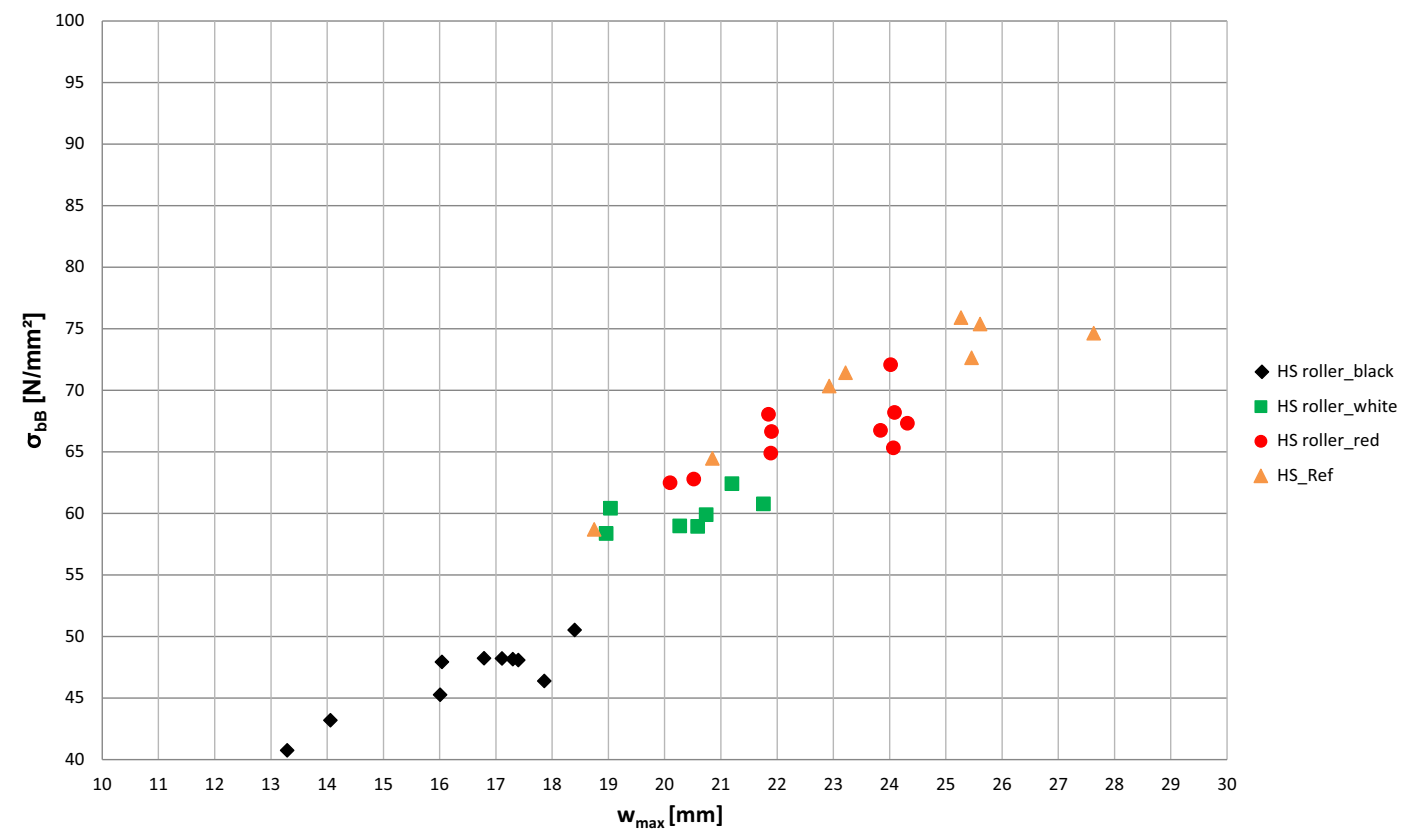

Fig. 3 Results for series 'HS glass with roller coating on side exposed to tensile bending stress'. (Color figure online)

Table 3 Statistical evaluation of the HS glass series

\begin{tabular}{|c|c|c|c|c|c|}
\hline Manufacturing process & Location of enamel & & Black & Red & White \\
\hline \multirow[t]{3}{*}{ Screen printing } & $\begin{array}{l}\text { Surface under } \\
\text { tension }\end{array}$ & $\begin{array}{l}\text { Normal distribution (confidence level } \\
95 \%, 5 \% \text { fractile) (MPa) }\end{array}$ & 54.99 & 69.38 & 47.27 \\
\hline & & Mean value $(\mathrm{MPa})$ & 61.63 & 81.29 & 59.10 \\
\hline & & Standard deviation & 2.31 & 4.14 & 4.12 \\
\hline \multirow[t]{3}{*}{ Roller coating } & $\begin{array}{l}\text { Surface under } \\
\text { tension }\end{array}$ & $\begin{array}{l}\text { Normal distribution (confidence level } \\
95 \%, 5 \% \text { fractile) }(\mathrm{MPa})\end{array}$ & 38.39 & 58.36 & 55.32 \\
\hline & & Mean value (MPa) & 46.66 & 66.43 & 59.95 \\
\hline & & Standard deviation & 2.88 & 2.81 & 1.38 \\
\hline
\end{tabular}

The results can be summed up as follows:

- The reference samples show a high dispersion of failure stresses despite the sprinkling with corundum.

- For the reference samples the mean value of the tensile bending strength is $70.4 \mathrm{MPa}$ and the fractile value $51.9 \mathrm{MPa}$ (confidence level $95 \%$, fractile $5 \%)$.

- Enamel on the side exposed to tensile bending stress: Except for the "roller coating, black" series, the minimum bending strength of $45 \mathrm{MPa}$ was reached for all other colours and manufacturing processes.

\subsubsection{Thermally toughened (fully toughened -FT) glass series}

In Figs. 4 and 5 the failure stress values are given for each manufacturing process. Also shown are the failure stress values for the un-enamelled reference samples. The statistical evaluation of all series is listed in Table 4.

The results can be summed up as follows:

- For the reference samples the mean value of the tensile bending strength is $145.7 \mathrm{MPa}$ and the fractile value 127.2 MPa (confidence level $95 \%$, fractile $5 \%$ ). The minimum bending strength of $120 \mathrm{MPa}$ for FT was reached. 


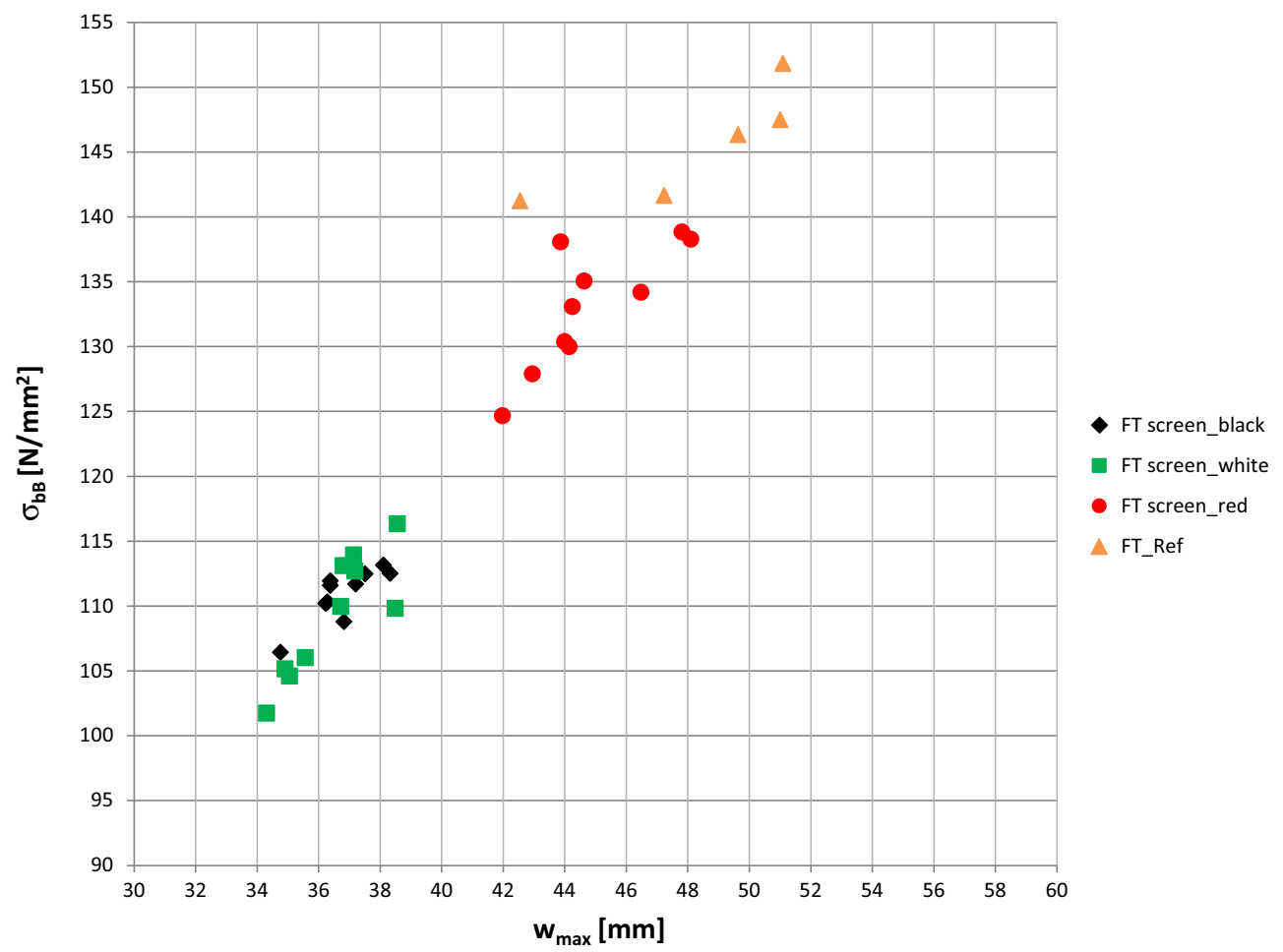

Fig. 4 Results for series 'FT glass with screen printing on side exposed to tensile bending stress'. (Color figure online)



Fig. 5 Results for series 'FT glass with roller coating on side exposed to tensile bending stress'. (Color figure online) 
Table 4 Statistical evaluation of the FT glass series

\begin{tabular}{|c|c|c|c|c|c|}
\hline Manufacturing process & Location of enamel & & Black & Red & White \\
\hline \multirow[t]{3}{*}{ Screen printing } & \multirow[t]{3}{*}{$\begin{array}{l}\text { Surface under } \\
\text { tension }\end{array}$} & $\begin{array}{l}\text { Normal distribution (confidence level } \\
95 \%, 5 \% \text { fractile) }(\mathrm{MPa})\end{array}$ & 105.02 & 119.34 & 95.63 \\
\hline & & Mean value (MPa) & 110.89 & 133.05 & 109.34 \\
\hline & & Standard deviation & 2.04 & 4.77 & 4.77 \\
\hline \multirow[t]{3}{*}{ Roller coating } & \multirow[t]{3}{*}{$\begin{array}{l}\text { Surface under } \\
\text { tension }\end{array}$} & $\begin{array}{l}\text { Normal distribution (confidence level } \\
95 \%, 5 \% \text { fractile) }(\mathrm{MPa})\end{array}$ & 85.28 & 103.36 & 99.24 \\
\hline & & Mean value (MPa) & 98.46 & 113.96 & 110.08 \\
\hline & & Standard deviation & 4.59 & 3.69 & 3.77 \\
\hline
\end{tabular}

- Enamel on the side exposed to tensile bending stress: For all colours and manufacturing processes a minimum bending strength higher than $75 \mathrm{MPa}$ was reached.

\subsubsection{Thermally toughened and heat soaked (FT-HST) glass series}

In Figs. 6 and 7 the failure stress values are given for each manufacturing process. Also shown are the failure stress values for the un-enamelled reference samples. The statistical evaluation of all series is listed in Table 5 .

The results can be summed up as follows:

- For the reference samples the mean value of the tensile bending strength is $134.4 \mathrm{MPa}$ and the fractile value $126.5 \mathrm{MPa}$ (confidence level $95 \%$, fractile $5 \%$ ). The minimum bending strength of $120 \mathrm{MPa}$ for FT was reached.

- Enamel on the side exposed to tensile bending stress: For all colours and manufacturing processes a minimum bending strength higher than $75 \mathrm{MPa}$ was reached.

\subsubsection{Summary of results}

The colours investigated in the present research project (black, red, white) and the application processes (screen printing, rolling coating) lead to different tensile bending strengths. A result which is to be traced back essentially to the different colour compositions of the enamels (different size of the colour grains, viscosity of the dyes, percentage of flow system, which vary depending on the manufacturing process) as well as the different thicknesses of their coatings. These factors lead to different parameters in the fusing or tempering process (duration, temperature) which can have an influence on the bending strengths. In order to determine the influence of the individual parameters, the colour compositions and the fusing parameters would need to be known. On this basis the thermal processes could be numerically simulated and optimised.

The samples with thinner enamel coating (screen printing, approximately $45 \mu \mathrm{m}$ coating thickness) tend to have greater strengths than thicker coatings (roller coating, approximately $75 \mu \mathrm{m}$ coating thickness). To give a more precise statement, coatings of greater thickness would need to be tested.

The tensile bending strengths ascertained for enamelled glass panes are, in some cases, significantly greater than the minimum bending strengths specified in the product standards (enamel on the side exposed to tensile bending stress), especially the enamel coatings produced by screen printing.

However to use these greater bending strengths as characteristic strength values for dimensioning of the glazing more precise parameters would need to be established regarding, for example, manufacturing and fusing processes, colour tint and colour composition and coating thickness. The reproducibility of these parameters would also have to be proven, e.g. within the framework of a National or European Technical Approval.

\subsection{Fracture mirror analysis}

\subsubsection{General}

The structure and appearance of the fracture surfaces allow for statements on the nature and size of the fracture as well as on the resulting failure stresses. For this 




- FT-HST screen_black - FT-HST screen_red - FT-HST screen_white $\triangle F T-H S T \_R e f$

Fig. 6 Results for series 'FT-HST glass with screen printing on side exposed to tensile bending stress'. (Color figure online)



- FT-HST_roller_black - FT-HST roller_red - FT-HST roller_white $\triangle F T$ - HST_Ref

Fig. 7 Results for series 'FT-HST glass with roller coating on side exposed to tensile bending stress'. (Color figure online) 
Table 5 Statistical evaluation of the FT-HST glass series

\begin{tabular}{|c|c|c|c|c|c|}
\hline Manufacturing process & Location of enamel & & Black & Red & White \\
\hline \multirow[t]{3}{*}{ Screen printing } & \multirow[t]{3}{*}{$\begin{array}{l}\text { Surface under } \\
\text { tension }\end{array}$} & $\begin{array}{l}\text { Normal distribution (confidence level } \\
95 \%, 5 \% \text { fractile) }(\mathrm{MPa})\end{array}$ & 100.33 & 113.59 & 98.08 \\
\hline & & Mean value (MPa) & 105.33 & 121.58 & 104.94 \\
\hline & & Standard deviation & 1.74 & 2.78 & 2.38 \\
\hline \multirow[t]{3}{*}{ Roller coating } & \multirow[t]{3}{*}{$\begin{array}{l}\text { Surface under } \\
\text { tension }\end{array}$} & $\begin{array}{l}\text { Normal distribution (confidence level } \\
95 \%, 5 \% \text { fractile) }(\mathrm{MPa})\end{array}$ & 79.06 & 81.23 & 88.11 \\
\hline & & Mean value (MPa) & 93.01 & 94.92 & 98.01 \\
\hline & & Standard deviation & 4.85 & 4.76 & 3.44 \\
\hline
\end{tabular}

Fig. 8 Typical appearance of a fracture mirror

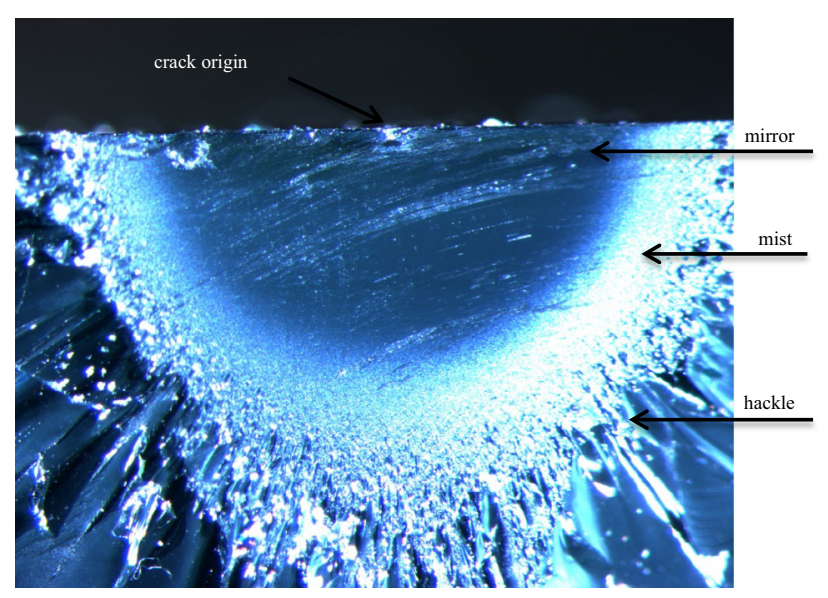

purpose a closer look at the structure of the fracture surface is required and light microscopic studies were performed.

At the starting point of a crack a so-called fracture mirror is created. A typical appearance of such a fracture mirror shows Fig. 8.

If the smooth fracture mirror is clearly developed, it is a sign of slow crack propagation. Correspondingly if the crack propagation is fast the shape is less distinctive. In principle the fracture mirror radius can be measured and thus the impacting energy that leads to the failure stress can be calculated. However the measurements may have relatively large variations (Wagner 2012), since the radii cannot be measured very accurately and are more or less subjective. In addition derived relationships between fracture mirror radius and failure stresses, for example by (Shand 1965), are valid only for annealed float glass, as constant stresses are assumed over the cross section in the area of the crack.

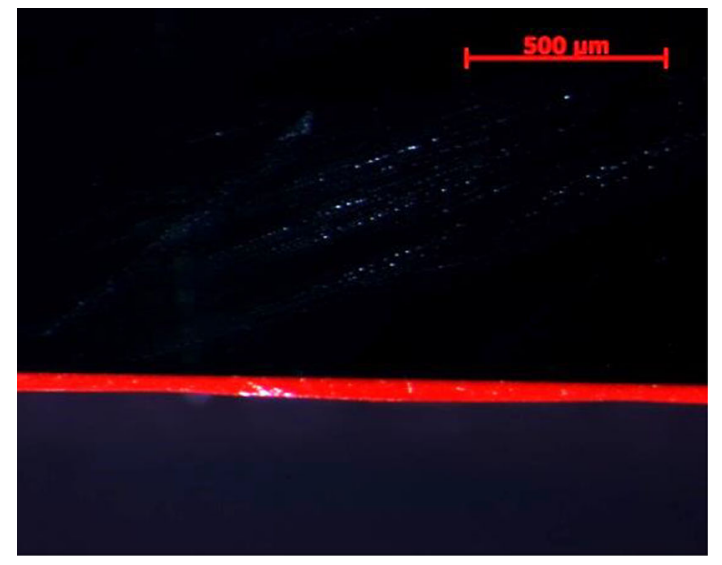

Fig. 9 Roller coated HS glass sample with uneven coating (red). (Color figure online)

\subsubsection{Approach}

A light optical microscope with double magnification was used to examine the samples. For the investigations 


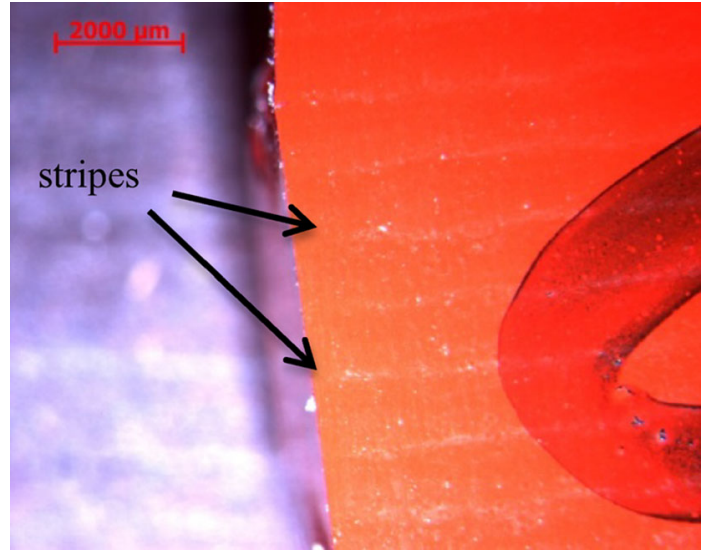

Fig. 10 Roller coated HS glass sample with stripe pattern

the destroyed specimen of the four point bending tests were used. Therefore, the fragments of the specimen with recognizable fracture surfaces were used. Only fragments of the HS glass series could be used for the examinations because the fragments of the specimen from FT glass were too small to locate the fracture origin exactly. In general the fracture origin of all specimen was in the area between the bending rollers of the four point bending test-setup.

The light was induced by different light sources on the sample. The adjustment of the light is of great importance as the image sharpness and the visible points are influenced by it.

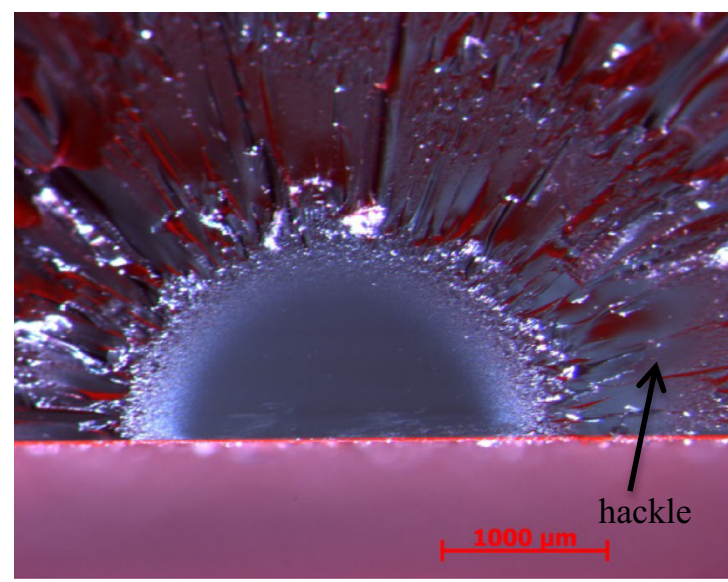

Sample: HS glass, screen printed, red

Tensile bending stress experimetally determined: $86.7 \mathrm{MPa}$

\subsubsection{Image evaluation}

- The glass surfaces of the samples located under the enamel coating were plane and no preliminary damages could be seen.

- Partly the enamel coating of some roller coated specimen was uneven (see Fig. 9).

- The stripes pattern of the roller was visible at some roller coated samples (see Fig. 10).

- Some samples had chipping at the surface of the crack origin and were therefore not examinable.

- The higher the experimentally determined bending stresses the more distinctive is the "hackle" area and the smaller the fracture mirror radius (see Fig. 11).

- It was not possible to determine failure stresses out of the images which corresponded with the experimentally determined values.

\section{Conclusion}

In (Krampe 2013) and in the present research (Siebert and Maniatis 2015) it was shown that different factors such as the colour composition, the application process or the thickness of the enamel result in different reductions of the tensile bending strength values compared to non-enamelled glass. But in some cases these tensile bending strength values are significantly greater than the minimum bending strengths specified in the product standards (enamel on the side exposed to tensile bend-

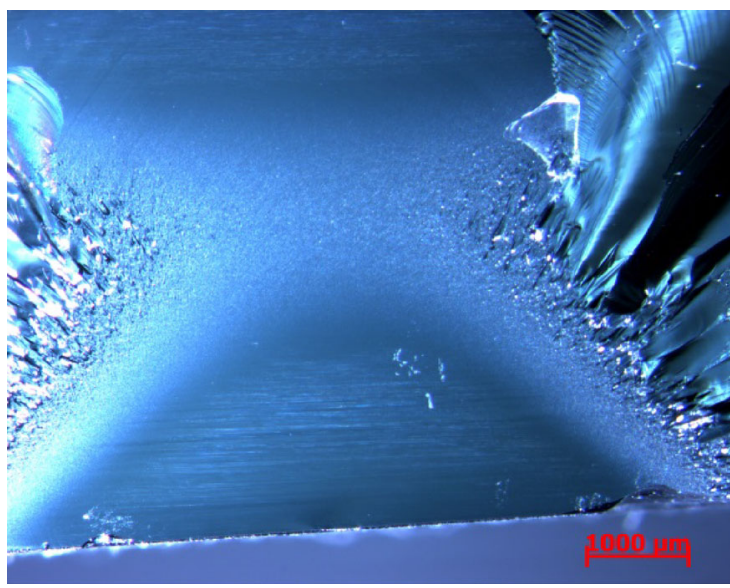

Sample: HS glass, screen printed, white

Tensile bending stress experimetally determined: $58.1 \mathrm{MPa}$

Fig. 11 Fracture mirror of different samples 
ing stress), especially the enamel coatings produced by screen printing. However to use these greater bending strengths as characteristic values for dimensioning of the glazing more precise parameters would need to be established and the reproducibility of these parameters would also have to be guaranteed. Nevertheless the values which have been adopted and applied for decades already in the product standards for enamelled fully toughened glass and enamelled heat soak tested fully toughened glass lie on the safe side and can still be used for design.

The samples of the heat strengthened glass series showed a high dispersion of failure stresses. To get reliable statements the number of samples would need to be increased.

The analysis of the mirror fracture is quite extensive and only possible if the glass fragments are big enough to identify the mirror fracture. Therefore only the HS glass samples could be examined. If there are any damages (chipping) in the area of the crack origin the mirror fracture is damaged and not visible anymore. In principle the fracture mirror radius can be measured and thus the impacting energy that leads to the failure stress can be calculated. Since the radii could not be measured very accurately the measurements had large variations. It was not possible to determine failure stresses out of the images which corresponded with the experimentally determined values. Basically it could be observed that the higher the experimentally determined bending stresses the more distinctive is the "hackle" area and the smaller the fracture mirror radius. To get reliable results more samples have to be evaluated.

\section{References}

BF-Bulletin 015/2013 "Guideline for assessing the visual quality of enamelled glass"

EN 1288-3: 2000-09 Glass in Building - Determination of the Tensile Strength of Glass - Part 3: Test With Sample Supported on Two Sides (Four-Point Bending Procedure)

EN 1863-1: 2012-02 Glass in Building - Heat-Strengthened Soda-Lime-Silicate Glass - Part 1: Definition and Description

EN 12150-1: 2000-11 Glass in Building - Thermally-Toughened Soda-Lime-Silicate Safety Glass - Part 1: Definition and Description

Krampe, P.: Zur Festigkeit emaillierter Gläser. Dissertation, Technische Universität Dresden (2013)

Shand, E.B.: Strength of glass-the Griffith method revised. J Am Ceram Soc 48, 43-49 (1965)

Siebert, G., Maniatis, I.: Untersuchungen zur Biegezugfestigkeiten von emaillierten Gläsern, Forschungsbericht - Nr. b-01-14-24, Universität der Bundeswehr (2015)

Technical Information "Flat Glass" from the Ferro Corporation, 09/2012

Technische Regel RAL-RG 529 A3:2007-07: Email(le) und emaillierte Erzeugnisse -Begriffsbestimmungen/Bezei chnungsvorschriften, Deutsches Institut für Gütesicherung und Kennzeichnung e.V

Wagner, Ekkehard: Glasschäden, Oberflächenbeschädigungen, Glasbrüche in Theorie und Praxis. Fraunhofer IRB Verlag, Stuttgart (2012)

Weller, B., Reich, S.: Glasbau-Praxis - Band 1: Grundlagen. Konstruktion und Bemessung. 3. überarbeitete und erweiterte Auflage. Beuth Verlag, Berlin (2013) 